\title{
Changing views of the evolution of immunity
}

\section{Larry J. Dishaw* and Gary W. Litman}

Division of Molecular Genetics, Department of Pediatrics, University of South Florida, Tampa, FL, USA

*Correspondence: Idishaw@health.usf.edu

\section{Edited by:}

Claudia Kemper, King's College London, UK

Reviewed by:

Claudia Kemper, King's College London, UK

Views on the evolution of immunity have been redefined as studies in protostomes, invertebrate deuterostomes, and various vertebrates have elucidated molecular details of host defense (Litman and Cooper, 2007; Boehm, 2012). Diverse species possess vast repertoires of immune related defenses, which have evolved into sophisticated, integrated networks (Rast and Messier-Solek, 2008; Messier-Solek et al., 2010). Certain components of immune defense represent either homologous structures or reflect novel approaches to confronting pathogens and other environmental influences [e.g., VLRs in agnathans (Boehm et al., 2012)]. Disparate diversification mechanisms and exceptional sophistication in immune mediators in some species blur distinctions between innate and adaptive immunity, the latter of which is viewed traditionally as a vertebrate adaptation (Litman et al., 2005; Messier-Solek et al., 2010; Boehm, 2011) associated with extensive somatic diversity, antigenspecific affinity maturation, and memory (Flajnik and Kasahara, 2010; Boehm, 2012). Innate immunity, specifically the recognition of microbe-associated molecular patterns by pattern recognition receptors (PRRs), has taken center stage owing to its capacity to shape adaptive immunity (Schenten and Medzhitov, 2011). PRRs [e.g., toll-like receptors (TLRs)], also contribute significantly to immune homeostasis (Medzhitov, 2010; Carvalho et al., 2012). In this special issue we explore topics that are continuing to reshape our interpretations of immune evolution.

Historically, transplantation immunology framed our understanding of immunological recognition and the interplay between immunoglobulin domain-containing receptors, co-receptors, and the major histocompatibility complex (MHC) (Brent, 2003). These earlier concepts were extended to address graft rejection in jawless vertebrates as well as select invertebrates (Finstad and Good, 1964; Hildemann and Thoenes, 1969; Mayer et al., 2002; Little et al., 2005; Kvell et al., 2007). Today, various models of allorecognition are recognized, some of which are restricted to certain phyla (Buss, 1987), and can be traced to the ancestors of sessile invertebrates (Dishaw and Litman, 2009). Broad rules govern discrimination between conspecifics (Rosengarten and Nicotra, 2011). Nydam and De Tomaso (2011) update our understanding of the evolution of allorecognition, emphasizing commonality in the systems that generate polymorphisms, and discuss how genetic diversity is maintained.

Extensive variation in immune genes traditionally has been equated with the immunoglobulin and $\mathrm{T}$ cell receptor gene loci in B and T lymphocytes, respectively, as well as in some MHC loci (Hughes, 2002). Recent studies in some invertebrate deuterostomes provide evidence for expansion and germline diversification of immune receptor repertoires. Buckley and Rast (2012) demonstrate lineage-specific properties among expanded sea urchin TLRs. Their findings indicate that: (1) some antigen binding sites may be coevolving with variable ligands, (2) TLR subfamilies are utilized differently between larval and adult coelomocytes, and (3) sea urchin TLRs most likely represent immune surveillance molecules. Satake and Sekiguchi (2012) review the evolution and functional diversification of TLRs among deuterostomes, highlighting a reduced repertoire in the tunicate, Ciona intestinalis. Only two TLRs can be detected in this species, with presumed hybrid functionality in vitro (Sasaki et al., 2009). Interestingly, neither TLR1 nor TLR2 recognizes bacterial lipopolysaccharide (LPS), suggesting that Ciona utilizes other mechanisms to detect LPS or that an accessory molecule(s) is involved.

Drosophila melanogaster (fruit fly) uses complex alternative RNA splicing to diversify the Down's syndrome cell adhesion molecule (DSCAM), a multiexonic receptor implicated in neuronal patterning (Shi and Lee, 2012). Some DSCAM isoforms serve as PRRs in peripheral hemocytes and exhibit increased specificity for distinct targets (Watson et al., 2005; Brites et al., 2008; Chou et al., 2009). These findings are reminiscent of the fibrinogen-related proteins (FREPs) (Adema et al., 1997; Zhang et al., 2004), which consist of fibrinogen and immunoglobulin superfamily-related domains that can undergo somatic mutation and gene conversion. Individual somatic lineages expressing FREPs respond to specific parasite burdens (Mone et al., 2010). Smith (2012) reviews Sp185/333 genes, a large family of innate receptors in sea urchin expressed in hemocytes. Variation in genes encoding Sp185/333 receptors arises via complex DNA rearrangements and may be influenced by persistent antigenic sources (Buckley et al., 2008; Dheilly et al., 2009).

Not all immune receptors are restricted to foreign determinants (Rabinovich and Croci, 2012). Some glycans can be found on both host and microbial surfaces (Davicino et al., 2011). Vasta et al. (2012) describe an apparent paradox among galectins, which until recently were considered essential in self-recognition (Rabinovich and Croci, 2012). Galectins now are considered PRRs that recognize related glycans on microbes (Sato et al., 2009). PRRs are thought to interact only with microbial products (Kawai and Akira, 2010); some, such as galectins, also may possess discriminatory properties (van Vliet et al., 2008). Galectin self-recognition may require interaction with accessory molecules on self-cells and warrants further investigation.

The role of PRRs in symbiotic relationships likely is ancient (Bosch, 2012), involving complex host-microbial interactions at the surface of mucosal tissues (Duerkop et al., 2009; Round 
et al., 2011; Wells et al., 2011; Hill et al., 2012). Collins et al. (2012) describe a PRR that may govern such interactions between the bobtail squid and Vibrio fisheri, a bacterial symbiont of the light organ. Immune systems appear to have evolved mechanisms that discriminate among symbionts and pathogens, while promoting the former (Speckman et al., 2003; Lee and Mazmanian, 2010; Nyholm and Graf, 2012).

There has been a tendency to oversimplify or even ignore the broader roles of PRRs in host physiology. Arrieta and Finlay (2012) review the complex strategies that are used by gut bacteria to modulate immune homeostasis. The complex roles of adaptive immunity among vertebrates further complicates the roles of PRRs in homeostasis (Lee and Mazmanian, 2010; Hooper et al., 2012). Dishaw et al. (2012) argue that Ciona intestinalis, a protochordate, can help define host and microbe interactions at mucosal surfaces. Presumably, rules and relationships that govern homeostasis in this system may help reveal how perturbations can lead to a broad range of intestinal pathologies in higher vertebrates.

Specific molecules have been implicated in intestinal homeostasis and include alkaline phosphatase-intestinal (Alpi), a member of the alkaline phosphatase (Alp) family. One possible role for these molecules is the detoxification of LPS, which in turn minimizes innate responses to commensal or beneficial microbial communities (Beumer et al., 2003; Bates et al., 2007; Lalles, 2010). Yang et al. (2012) describe the complex evolutionary patterns of Alpi

\section{REFERENCES}

Adema, C. M., Hertel, L. A., Miller, R. D., and Loker, E. S. (1997). A family of fibrinogen-related proteins that precipitates parasite-derived molecules is produced by an invertebrate after infection. Proc. Natl. Acad. Sci. U.S.A. 94, 8691-8696.

Arrieta, M. C., and Finlay, B. B. (2012). The commensal microbiota drives immune homeostasis. Front. Immunol. 3:33. doi: 10.3389/fimmu.2012.00033

Bates, J. M., Akerlund, J., Mittge, E., and Guillemin, K. (2007). Intestinal alkaline phosphatase detoxifies lipopolysaccharide and prevents inflammation in zebrafish in response to the gut microbiota. Cell Host Microbe 2, 371-382.

Beumer, C., Wulferink, M., Raaben, W., Fiechter, D., Brands, R., and Seinen, W. (2003). Calf intestinal alkaline phosphatase, a novel therapeutic drug for lipopolysaccharide (LPS)-mediated diseases, attenuates LPS toxicity in mice and piglets. J. Pharmacol. Exp. Ther. 307, 737-744.

Boehm, T. (2011). Design principles of adaptive immune systems. Nat. Rev. Immunol. 11, 307-317.

Boehm, T. (2012). Evolution of vertebrate immunity. Curr. Biol. 22, R722-R732.

Boehm, T., McCurley, N., Sutoh, Y., Schorpp, M., Kasahara, M., and Cooper, M. D. (2012). VLR-based adaptive immunity. Annu. Rev. Immunol. 30, 203-220.
Bosch, T. C. (2012). Understanding complex host-microbe interactions in Hydra. Gut Microbes 3, 345-351.

Brent, L. (2003). The 50th anniversary of the discovery of immunologic tolerance. N. Engl. J. Med. 349, 1381-1383.

Brites, D., McTaggart, S., Morris, K., Anderson, J., Thomas, K., Colson, I., et al. (2008). The DSCAM homologue of the crustacean Daphnia is diversified by alternative splicing like in insects. Mol. Biol. Evol. 25, 1429-1439.

Buckley, K. M., Munshaw, S., Kepler, T. B., and Smith, L. C. (2008). The 185/333 gene family is a rapidly diversifying host-defense gene cluster in the purple sea urchin Strongylocentrotus purpuratus. J. Mol. Biol. 379, 912-928.

Buckley, K. M., and Rast, J. P. (2012). Dynamic evolution of toll-like receptor multigene families in echinoderms. Front. Immunol. 3:136. doi: 10.3389/ fimmu.2012.00136

Buss, L. W. (1987). The Evolution of Individuality. Princeton: Princeton University Press.

Carvalho, F. A., Aitken, J. D., Vijay-Kumar, M., and Gewirtz,A. T. (2012). Toll-like receptor-gut microbiota interactions: perturb at your own risk! Annu. Rev. Physiol. 74, 177-198.

Chou, P. H., Chang, H. S., Chen, I. T., Lin, H. Y., Chen, Y. M., Yang, H. L., et al. (2009). The putative invertebrate adaptive immune protein Litopenaeus vannamei DSCAM (LvDSCAM) is the first reported DSCAM to lack a

genes, which appear to be evolving independently in vertebrate, non-vertebrate and insect lineages. All four zebrafish Alp genes are shown to be expressed in the intestine, where alp 3 is expressed exclusively. The authors propose that intestinal expression of Alp may be an ancestral trait as alkaline-phosphatase-mediated LPS detoxification likely is central to the stability of gut microbe and host interactions.

Phylogenetic considerations, including the use of non-traditional models, have been instrumental in forging new thinking among immunologists (Loker et al., 2004). It is becoming increasingly clear that the immune system may have evolved, not only to recognize potential pathogens but also to help sustain and stabilize beneficial associations at the surface of mucosal tissues. Loker (2012) considers symbiosis as a driver of evolutionary novelty on both sides of the host-parasite struggle. In this broad, topical overview, host immunity is a pervasive requirement and the immune evolutionary process is seen to be influenced by conflict with parasites and/or the need to cooperate with symbionts. The work presented in this series already is proving critical in terms of broadening our view of immune complexity and the multifaceted role of the host-microbe dialog in maintaining homeostasis. Critical departures from our traditional views of immune defense are being revealed in detailed studies of alternative model systems and in turn are reshaping our understanding of immunity in conventional systems.

transmembrane domain and cytoplasmic tail. Dev. Comp. Immunol. 33, 1258-1267.

Collins, A. J., Schleicher, T. R., Rader, B. A., and Nyholm, S. V. (2012). Understanding the role of host hemocytes in a squid/vibrio symbiosis using transcriptomics and proteomics. Front. Immunol. 3:91. doi: 10.3389/ fimmu.2012.00091

Davicino, R. C., Elicabe, R. J., Di Genaro, M. S., and Rabinovich, G. A. (2011) Coupling pathogen recognition to innate immunity through glycan-dependent mechanisms. Int Immunopharmacol. 11, 1457-1463.

Dheilly, N. M., Nair, S. V., Smith, L. C., and Raftos, D. A. (2009). Highly variable immune-response proteins (185/333) from the sea urchin, Strongylocentrotus purpuratus: proteomic analysis identifies diversity within and between individuals. J. Immunol. 182, 2203-2212.

Dishaw, L. J., Flores-Torres, J. A., Mueller, M. G., Karrer, C. R., Skapura, D. P., Melillo, D., et al. (2012). A basal chordate model for studies of gut microbial immune interactions. Front. Immunol. 3:96. doi: 10.3389/fimmu.2012.00096

Dishaw, L. J., and Litman, G. W. (2009). Invertebrate allorecognition: the origins of histocompatibility. Curr. Biol. 19, R286-R288.

Duerkop, B. A., Vaishnava, S., and Hooper, L. V. (2009). Immune responses to the microbiota at the intestinal mucosal surface. Immunity 31, 368-376.
Finstad, J., and Good, R. A. (1964). The evolution of the immune response. III. Immunologic responses in the lamprey. J. Exp. Med. 120, 1151-1168.

Flajnik, M. F., and Kasahara, M. (2010). Origin and evolution of the adaptive immune system: genetic events and selective pressures. Nat. Rev. Genet. 11, 47-59.

Hildemann, W. H., and Thoenes, G. H. (1969). Immunological responses of Pacific hagfish. I. Skin transplantation immunity. Transplantation 7, 506-521.

Hill, D. A., Siracusa, M. C., Abt, M. C., Kim, B.S., Kobuley, D., Kubo, M., et al. (2012). Commensal bacteria-derived signals regulate basophil hematopoiesis and allergic inflammation. Nat. Med. 18, 538-546.

Hooper, L. V., Littman, D. R., and MacPherson, A. J. (2012). Interactions between the microbiota and the immune system. Science 336, 1268-1273.

Hughes, A. L. (2002). Natural selection and the diversification of vertebrate immune effectors. Immunol. Rev. 190, 161-168.

Kawai, T., and Akira, S. (2010). The role of pattern-recognition receptors in innate immunity: update on Toll-like receptors. Nat. Immunol. 11, 373-384.

Kvell, K., Cooper, E. L., Engelmann, P., Bovari, J., and Nemeth, P. (2007). Blurring borders: innate immunity with adaptive features. Clin. Dev. Immunol. 2007, 83671. 
Lalles, J. P. (2010). Intestinal alkaline phosphatase: multiple biological roles in maintenance of intestinal homeostasis and modulation by diet. Nutr. Rev. 68, 323-332.

Lee, Y.K., and Mazmanian, S. K. (2010). Has the microbiota played a critical role in the evolution of the adaptive immune system? Science 330, 1768-1773.

Litman, G. W., Cannon, J. P., and Dishaw, L. J. (2005). Reconstructing immune phylogeny: new perspectives. Nat. Rev. Immunol. 5, 866-879.

Litman, G. W., and Cooper, M. D. (2007). Commentary: why study the evolution of immunity? Nat. Immunol. 8, 547-548.

Little, T. J., Hultmark, D., and Read, A. F. (2005). Invertebrate immunity and the limits of mechanistic immunology. Nat. Immunol. 6, 651-654.

Loker, E. S. (2012). Macroevolutionary Immunology: a role for immunity in the diversification of animal life. Front. Immunol. 3:25. doi: 10.3389/ fimmu.2012.00025

Loker, E. S., Adema, C. M., Zhang, S.-M., and Kepler, T. B. (2004). Invertebrate immune systems - not homogeneous, not simple, not well understood. Immunol. Rev. 198, 10-24.

Mayer, W. E., Uinuk-Ool, T., Tichy, H., Gartland, L. A., Klein, J., and Cooper, M.D. (2002). Isolation and characterization of lymphocyte-like cells from a lamprey. Proc. Natl. Acad. Sci. U.S.A. 99, 14350-14355.

Medzhitov, R. (2010). Innate immunity: quo vadis? Nat. Immunol. 11,551-553.

Messier-Solek, C., Buckley, K. M., and Rast, J. P. (2010). Highly diversified innate receptor systems and new forms of animal immunity. Semin. Immunol. 22, 39-47.
Mone, Y., Gourbal, B., Duval, D., Du, P. L., Kieffer-Jaquinod, S., and Mitta, G. (2010). A large repertoire of parasite epitopes matched by a large repertoire of host immune receptors in an invertebrate host/parasite model. PLoS Negl. Trop. Dis. 4:e813. doi: 10.1371/ journal.pntd.0000813

Nydam, M. L., and De Tomaso, A. W. (2011). Creation and maintenance of variation in allorecognition Loci: molecular analysis in various model systems. Front. Immunol. 2:79. doi: 10.3389/fimmu.2011.00079

Nyholm, S. V., and Graf, J. (2012). Knowing your friends: invertebrate innate immunity fosters beneficial bacterial symbioses. Nat. Rev. Microbiol. 10, 815-827.

Rabinovich, G.A., and Croci, D. O. (2012). Regulatory circuits mediated bylectinglycan interactions in autoimmunity and cancer. Immunity 36, 322-335.

Rast, J. P., and Messier-Solek, C. (2008). Marine invertebrategenome sequences and our evolving understanding of animal immunity. Biol. Bull. 214, 274-283.

Rosengarten, R. D., and Nicotra, M. L. (2011). Model systems of invertebrate allorecognition. Curr. Biol. 21, R82-R92.

Round, J.L., Lee, S. M., Li, J., Tran, G., Jabri, B., Chatila, T.A., et al. (2011). The Tolllike receptor 2 pathway establishes colonization by a commensal of the human microbiota. Science 332, 974-977.

Sasaki, N., Ogasawara, M., Sekiguchi, T., Kusumoto, S., and Satake, H. (2009). Toll-like receptors of the ascidian Ciona intestinalis: prototypes with hybrid functionalities of vertebrate Toll-like receptors. J. Biol. Chem. 284, 27336-27343.
Satake, H., and Sekiguchi, T. (2012). Tolllike receptors of deuterostome invertebrates. Front. Immunol. 3:34. doi: 10.3389/fimmu.2012.00034

Sato, S., St-Pierre, C., Bhaumik, P., and Nieminen, J. (2009). Galectins in innate immunity: dual functions of host soluble beta-galactoside-binding lectins as damage-associated molecular patterns (DAMPs) and as receptors for pathogen-associated molecular patterns (PAMPs). Immunol. Rev. 230, 172-187.

Schenten, D., and Medzhitov, R. (2011) The control of adaptive immune responses by the innate immune system. Adv. Immunol. 109, 87-124.

Shi, L., and Lee, T. (2012). Molecular diversity of DSCAM and self-recognition. Adv. Exp. Med. Biol. 739, 262-275.

Smith, L. C. (2012). Innate immune complexity in the purple sea urchin: diversity of the sp185/333 system. Front. Immunol. 3:70. doi: 10.3389/ fimmu.2012.00070

Speckman, R.A., Wright Daw, J.A., Helms, C., Duan, S., Cao, L., Taillon-Miller, P., et al. (2003). Novel immunoglobulin superfamily gene cluster, mapping to a region of human chromosome $17 \mathrm{q} 25$, linked to psoriasis susceptibility. Hum. Genet. 112, 34-41.

van Vliet, S. J., Garcia-Vallejo, J. J., and van Kooyk, Y. (2008). Dendritic cells and C-type lectin receptors: coupling innate to adaptive immune responses. Immunol. Cell Biol. 86, 580-587.

Vasta, G. R., Ahmed, H., Nita-Lazar, M., Banerjee, A., Pasek, M., Shridhar, S., et al. (2012). Galectins as self/non-self recognition receptors in innate and adaptive immunity: an unresolved paradox. Front. Immunol. 3:199. doi: 10.3389/fimmu.2012.00199
Watson, F. L., Püttmann-Holgado, R., Thomas, F., Lamar, D. L., Hughes, M. Kondo, M., et al. (2005). Extensive diversity of Ig-superfamily proteins in the immune system of insects. Science 309, 1874-1878.

Wells, J. M., Rossi, O., Meijerink, M., and van, B. P. (2011). Epithelial crosstalk at the microbiota-mucosal interface. Proc. Natl.Acad. Sci. U.S.A. 108(Suppl. 1), 4607-4614.

Yang, Y., Wandler, A. M., Postlethwait, J. H., and Guillemin, K. (2012). Dynamic evolution of the LPSdetoxifying enzyme intestinal alkaline phosphatase in zebrafish and other vertebrates. Front. Immunol. 3:314. doi: 10.3389/ fimmu.2012.00314

Zhang, S.-M., Adema, C. M., Kepler, T. B., and Loker, E. S. (2004). Diversification of Ig superfamily genes in an invertebrate. Science 305, 251-254.

Received: 30 April 2013; accepted: 06 May 2013; published online: 21 May 2013.

Citation: Dishaw LJ and Litman GW (2013) Changing views of the evolution of immunity. Front. Immunol. 4:122. doi:10.3389/fimmu.2013.00122

This article was submitted to Frontiers in Molecular Innate Immunity, a specialty of Frontiers in Immunology.

Copyright (c) 2013 Dishaw and Litman. This is an open-access article distributed under the terms of the Creative Commons Attribution License, which permits use, distribution and reproduction in other forums, provided the original authors and source are credited and subject to any copyright notices concerning any third-party graphics etc. 